\title{
VIDA Y VERDAD: AUTOBIOGRAFÍAS DE HÉLÈNE CIXOUS
}

\author{
LIFE AND TRUTH: HÉLÈNE CIXOUS'S AUTOBIOGRAPHIES
}

\author{
Marta SEGARRA \\ LEGS, Centre National de la Recherche Scientifique-CNRS / ADHUC, \\ Universitat de Barcelona \\ marta.segarra@cnrs.fr
}

Resumen: La literatura escrita por mujeres se ha considerado con frecuencia desde el prisma autobiográfico, como si las autoras fueran más proclives a la verdad autobiográfica, a contar sus vidas incluso en sus obras de ficción. Por ello, la crítica relaciona generalmente a las escritoras francesas contemporáneas con el género de la "autoficción". Hélène Cixous, especialmente en sus últimas obras, realiza por su parte un uso muy particular de la escritura autobiográfica, o de la relación entre vida y literatura, llevando este género hasta sus límites.

Palabras clave: Hélène Cixous. Autobiografía. Autoficción.

Abstract: Literature written by women has been often regarded in the light of autobiography, as if women writers were more prone to autobiographical truth, even in their fictional works. Thus, critics generally associate contemporary French women writers with the genre of autofiction. Hélène Cixous, especially in her last texts, uses autobiographical writing -or, in other words, associates life and literature-in a very particular way, pushing this genre to its limits. 
Key Words: Hélène Cixous. Autobiography. Autofiction.

\section{ESCRITURA AUTOBIOGRÁFICA Y GÉNERO}

La escritura autobiográfica está estrechamente asociada a la concepción moderna del sujeto (por ello las Confesiones de Rousseau se consideran con frecuencia una suerte de libro inaugural de este género literario), y las mujeres, en el Siglo de las Luces, quedaban excluidas de esta categoría, al ser consideradas, como mucho, sujetos menores. Sin embargo, dicha escritura se ha relacionado con frecuencia también, y de modo un tanto contradictorio, con lo femenino, pues la "autobiografía" se caracteriza, entre otros rasgos conceptuados como propios de las mujeres, por la expresión de la intimidad y de los sentimientos, y el interés por la esfera privada igual o más que por la pública (al contrario que las "memorias").

Al mismo tiempo, desde la modernidad literaria, la ficción se ha considerado usualmente el signo principal de literariedad en el campo de la prosa (véase Genette, 1991; Derrida, 1996b). Este criterio ha servido para situar la escritura autobiográfica (entendida como ajena a la ficción) en los márgenes de la literatura; muchos escritos de mujeres, siguiendo este razonamiento, eran colocados en este espacio periférico y, por ello, menor. El carácter real o pretendidamente autobiográfico de un número importante de obras escritas por mujeres en el siglo XX se ha tendido, así, a juzgar de forma cualitativa, como si ellas tuvieran menos aptitudes para la ficción, para la verdadera literatura ${ }^{1}$. En ciertos casos, la crítica incluso reduce los escritos de mujeres al puro testimonio, como si éste no estuviera siempre íntimamente ligado a la ficción ${ }^{2}$. La supuesta preferencia de las escritoras por las "literaturas íntimas" (Hubier, 2003) se ha explicado, así, por el narcisismo femenino o por la tendencia natural de las mujeres hacia la esfera privada e incluso "íntima", lo cual equivale a reducirlas al espacio

1. Véase la crítica que hacen de esta tendencia Smith (1987), Benstock (1988), Brodzki y Schenck (1988), Hewitt (1990) y Smith y Watson (1998).

2. Jacques Derrida dice a este propósito: “Il n'est pas de témoignage qui n'implique structurellement en lui-même la possibilité de la fiction, du simulacre, de la dissimulation, du mensonge et du parjure - c'està-dire aussi de la littérature, de l'innocente ou perverse littérature qui joue innocemment à pervertir toutes ces distinctions" (1996: 23). 
doméstico.

Sin embargo, y desde una perspectiva que se podría considerar opuesta, pues no trata de reducir el valor de los textos literarios escritos por mujeres sino, al contrario, de resaltarlo, otro tipo de crítica ha sugerido que el género autobiográfico es especialmente sensible a la diferencia sexual, en el sentido de que la escritura autobiográfica de mujeres se distinguiría de la de los hombres por una serie de características propias. Este presupuesto parte de la base de que, en textos tan ligados a la construcción de las identidades como son los autobiográficos, la cuestión del género parece ineludible (véase Lecarme \& Lecarme-Tabone, 1999: 93-124).

Así, una parte de la crítica feminista, especialmente anglófona ${ }^{3}$, sugirió que las autobiografías de las escritoras comparten algunos rasgos, como una cierta mirada hacia el cuerpo, una insistencia en la relación con las personas del entorno familiar (y, en especial, con la madre), así como un planteamiento distinto al de los hombres de la cuestión del "nombre propio" y de la autoría (Lecarme \& Lecarme-Tabone, 1999: 110-112). Pero esta corriente crítica insiste sobre todo en que cabría percibir un cierto modo de hablar de sí misma propio de las mujeres, más lateral y alusivo que cuando es un hombre quien escribe. Ello quizás es más patente en el pasado (o en otras culturas que la francesa, como por ejemplo la literatura francófona magrebí escrita por mujeres), cuando hablar de sí misma significaba para muchas mujeres transgredir una prohibición simbólica y social $^{4}$. Esta manera de acercarse al yo, que las protegería de los ataques o de la propia sensación de culpabilidad derivados de dicha transgresión, puede traducirse precisamente en una mezcla de autobiografía y de ficción novelesca.

Muchas autoras (aunque también muchos autores) combinan, pues, en sus obras la escritura autobiográfica y de ficción ${ }^{5}$. Cabe aclarar, sin embargo, que el "pacto autobiográfico" (Lejeune, 1975) implica tanto a la autora como al lector o lectora; con frecuencia, es la recepción de las obras escritas por mujeres lo que las deriva hacia lo autobiográfico, es decir, hacia el referente extratextual ${ }^{6}$ : por un lado, se cree que las autoras tienden

3. Véase los ensayos citados en la nota 1, así como Smith (1993) y Smith y Watson (1992).

4. El término "autoginografía" designa este modo autobiográfico que sería propio a las mujeres; véase Stanton (1987) y Brée (1986).

5. Viart y Vercier (2005: 42) proponen la noción de "fiction existentielle" para describir esta hibridez.

6. B. Didier (1981), por ejemplo, sostiene que el público lector de autobiografía siempre ha manifestado más curiosidad hacia los detalles verdaderos cuando provienen de una mujer que de un hombre, 
a privilegiar esta asociación con la realidad y, por otro, que las lectoras se identifican más que los lectores con el relato autobiográfico de una mujer que con el de un hombre. Ambas suposiciones quedan también por demostrar.

\section{LAAUTOFICCIÓN, ¿UN GÉNERO PARA LAS MUJERES?}

Muchas escritoras de las últimas décadas del siglo XX y de principios del XXI han reflexionado sobre la relación entre escritura y vida, o entre escritura y "verdad", analizando de qué modo la autobiografía y la ficción se acercan a lo que se podría llamar la verdad de una vida. Marguerite Duras afirmaba así que ella había escrito "le roman de sa vie", la novela de su vida, respondiendo a las preguntas sobre la "verdad" de L'Amant: "L'histoire de ma vie, de votre vie, n'existe pas [...]. Le roman de ma vie, de nos vies, oui, mais pas l'histoire" (en Lebelley, 1994: 10). Por su parte, Annie Ernaux recurre al término "verdad" para definir su proyecto literario, que se inscribe tanto en la escritura autobiográfica como "autosociobiográfica" (véase Thumerel, 2004).

Un caso polémico de la relación entre vida, escritura y "verdad" es el de Christine Angot, que se reveló al gran público con su libro titulado L'Inceste (1999), un relato entre autobiográfico y autoficcional. La autora acusó a editores y críticos de mezclar su "vida" y su "obra", pero abundó en la misma confusión, al combinar lo que podría llamarse un "fenómeno" editorial (un libro que vende) con una apuesta por la "verdad" mediante una escritura "de urgencia”, según los términos de Duras. En su libro Quitter la ville (2000), la misma Angot describe la "fabricación" del acontecimiento editorial que representó L'Inceste así como su recepción crítica (véase Fassin, 2001), y confiesa que juega con lo "verdadero" y lo "falso" en su escritura, que se basa en esta misma ambigüedad.

La obra de Angot podría encuadrarse en lo que se ha llamado la "autoficción", un término que ha acabado por tener un sentido tan amplio como "la ficcionalización de la experiencia vivida" (Colonna, 1989: 248)7, o de lo verdadero. Este género parecería, pues, particularmente apto para las escritoras que desean evitar sesgos de género en la recepción de sus obras (véase Jaccomard, 1993), lo cual afecta especialmente los relatos

especialmente en cuanto a confidencias sentimentales o sexuales. (1977).

7. Véase también Colonna (2004) y Darrieussecq (1996). La palabra fue forjada por Doubrovsky 
autobiográficos en tanto que enunciadores de "verdad". Otro ejemplo de confusión voluntaria entre realidad y ficción, por parte de una escritora perteneciente a una generación más joven que Angot, es el de Delphine de Vigan, que, en D'après une histoire vraie (obra galardonada con el premio Renaudot, 2015), describe irónicamente mediante una historia que se supone de ficción, pero cuyos personajes coinciden con la autora y su entorno, la pasión de los lectores y lectoras por una "historia verdadera", la de ciertos secretos familiares ligados al suicidio de su madre, que la autora contó en su libro anterior, Rien ne s'oppose à la nuit (2011).

Chloé Delaume, también marcada por una historia familiar trágica, practica por su parte "autoficciones experimentales", y ha publicado un ensayo sobre la autoficción y sus paradojas (La Règle du Je, 2010). Para acabar este breve panorama, sin pretensión alguna de exhaustividad, antes de pasar al análisis de un caso concreto de escritura autobiográfica reciente, cabe mencionar a la autora francoargelina Nina Bouraoui, que lleva a cabo en sus textos una búsqueda literaria tanto en referencia a su identidad comunitaria (definiéndose "ni francesa, ni argelina") como a su identidad sexual, en libros como Garçon manqué (2000) o Mes mauvaises pensées (Premio Renaudot, 2004).

\section{AUTOBIOGRAFÍAS DE HÉLÈNE CIXOUS}

La crítica encuadra habitualmente la obra literaria de Hélène Cixous dentro de lo que se ha dado en llamar las "escrituras del cuerpo", nacidas del Mouvement de Libération des Femmes-MLF que arrancó en los años sesenta del siglo XX y se oficializó a principios de los setenta. Escritoras como Annie Leclerc, Chantal Chawaf o la misma Hélène Cixous escribieron textos que combinaban autobiografía, ficción y ensayo, y que incluían experiencias vitales que no habían sido nunca, o casi nunca, tratadas en la literatura francesa, como la del embarazo y el parto. La hibridez genérica no sólo obedecía a la voluntad de ruptura con los géneros literarios bien definidos, sino también a la necesidad que tenían estas mujeres que participaron en el MLF de "decirse" (Djebar, 1985: 76) y "escribirse", como vía de conocimiento de sí mismas y como reivindicación de una

8. Véase la web de la escritora: $h t t p: / / w w w . c h l o e d e l a u m e . n e t$. (1975: 39).

9. "Il faut que la femme s'écrive", dice Hélène Cixous al principio de "Le rire de la Méduse" 
identidad individual y colectiva.

Hélène Cixous, a la que tomamos como caso de estudio debido al original uso que hace de la autobiografía, transpone sus circunstancias vitales (o lo que llama en varias ocasiones sus "heridas inaugurales") en textos que mezclan poesía y ficción para tratar temas tan universales como el nacimiento y la muerte, la supervivencia, el odio y el amor en el seno de la familia y del mundo. Asimismo, su propia concepción del sujeto, abierta y plural, impide que su obra se reduzca a la autobiografía en singular, término que, como veremos, en ella siempre debería utilizarse en plural.

Sus primeros libros, a los que el editor añadía el subtítulo "novela", volvían una y otra vez a los motivos fundamentales de su obra: la (no) pertenencia y la expulsión, experimentadas durante su infancia en la Argelia colonial; la separación respecto a los seres queridos (vivida tempranamente a causa de la muerte de su padre cuando era niña), a la que opone el cultivo de la memoria y de los sueños; la complejidad de los lazos que nos atan a los demás; la fluidez de las identificaciones (entre los sexos, pero también entre las especies...), que impide la fijación de cualquier identidad estable; y la familia como escenario de dramas y comedias que reflejan los de la Historia, entre otros temas comunes a la literatura universal.

Algunos críticos, sobre todo en la prensa, señalaron un "giro" autobiográfico en la obra de Cixous a partir del final de los años noventa, con la aparición de dos libros sobre su padre y su madre, respectivamente: OR - les lettres de mon père (1997) y Osnabrück (1999), y de manera más acentuada, a principios del nuevo milenio con Les Rêveries de la femme sauvage (2000a) y Le Jour où je n'étais pas là (2000b), que relatan experiencias de su infancia y juventud. Unos años más tarde, Ciguë. Vieilles femmes en fleurs (2008) empieza una serie de textos alrededor de la vejez extrema (la madre de la autora vivió más de cien años), que se presentan como un viaje a unas tierras incógnitas en literatura ${ }^{10}$, aventura que no se termina con el fallecimiento de la madre, Ève, ya que ésta se convierte en un personaje espectral en toda la obra posterior a su "marcha".

Es en 2013, sin embargo, cuando Hélène Cixous empieza un ciclo narrativo más explícitamente autobiográfico, aunque siempre de una forma muy personal, titulado Abstracts et brèves chroniques du temps, con el

10. Por alusión al título de uno de los libros de esta serie: Revirements - dans l'antarctique du cœur (2011). Véase también Boyer-Weinmann (2013), que dedica una parte de su ensayo a estas novelas de Cixous. 
libro Chapitre Los (2103), seguido de Corollaires d'un vœu (2015). En su libro siguiente, toma otra dirección en este mismo ámbito, ya que Gare d'Osnabrück à Jérusalem (2016a), así como su secuela, Correspondance avec le mur (2017), no vuelven a su vida pasada, sino que se sumergen en la historia de su familia materna, judía askenazí, con el fin de relatar las tragedias individuales que componen la gran Tragedia de la persecución y asesinato de los judíos por parte de los nazis.

\subsection{Nacer en más de un lugar}

Gare d'Osnabrück à Jérusalem obtuvo una muy buena acogida por parte del lectorado y de la crítica, que apreció en él una intensidad y una tensión especiales, quizás debidas a los habitantes de este relato, personas aparentemente desaparecidas que la escritura hace revivir, una "foule de morts [...] bien vivants dans les livres" (Cixous, 2016a: 18). El texto se acompaña, como la autora suele hacerlo en los últimos años, de imágenes, en este caso unos "sustantivos" dibujados por Pierre Alechinsky, que corresponden a palabras clave del relato, como Vertreibung, término alemán que significa "expulsión". Ya hemos mencionado que una de las "heridas inaugurales" de la autora, quizás la que resume todas las demás, es la experiencia de la exclusión (dehors) y del encierro (dedans), vivida en Argelia pero quizás, ya antes, en Alemania, donde Cixous declara haber nacido también; volveremos a esta cuestión del nacimiento.

Uno de los rasgos originales de Gare d'Osnabrück à Jérusalem con respecto a la escritura autobiográfica más habitual reside en el hecho de que la gran mayoría de historias que se cuentan en este libro pertenecen a una época anterior al nacimiento de la autora. Tal como observa un personaje, el relato no se basa en los recuerdos de la escritora ("Tu n'étais pas née, dit mon fils") sino en los de su madre, a lo cual ella replica: "J'ai les souvenirs d'Ève" (2016a: 30). La autobiografía se extiende así más allá de la propia subjetividad, recogiendo una "herencia", en este caso grave y dolorosa, pues se trata de las vivencias de su familia judía alemana en la época nazi.

De este modo, Osnabrück se convierte en una de las ciudades "natales" de la autora: la ciudad de los recuerdos felices de la infancia de la madre, y por lo tanto de la hija que los hereda, y a la vez "Zérosnabrück" "“zérojuif”; 2016a: 26), aquella que expulsó a todos sus judíos despojándoles incluso de la posibilidad de morir, ya que sólo podían ser asesinados, "ermordet", 
otra de las "palabras-veneno" (también llamadas "mot-crime" o "motabattoir"; 2016a: 47), como la infame Arisierung ("arianización"). La autora introduce estos términos alemanes, algunos de los cuales se hallan resaltados por los dibujos de Alechinski, con el fin de exorcizar su poder, en el sentido de los "poemas-exorcismo" que Henri Michaux (1945) escribió durante la ocupación alemana de Francia. La escritura, en este caso autobiográfica, tendría así para Cixous un valor curativo ya que ejerce de "contraveneno"11. Esta capacidad de la literatura remite a algunos relatos de supervivientes de los campos de concentración, como Primo Levi o Jorge Semprún, que afirmaron que la literatura les había salvado la vida, al salvaguardar su humanidad (y sabemos por "Volées d'humanité" [2010] el sentido profundo que adquiere esta palabra en Hélène Cixous) frente a la terrorífica deshumanización que se llevaba a cabo en los campos de la muerte.

Gare d'Osnabrück à Jérusalem es un texto autobiográfico que retorna, pues, a los orígenes, ya que esta palabra debe estar siempre en plural en relación con Cixous, quien afirma en Une autobiographie allemande: "Je suis le résultat de plus d'un pays natal" (2016b: 15). Los orígenes familiares de Hélène Cixous son, en efecto, múltiples, tanto por parte paterna como materna, pero sobre todo lo son por vocación: “J'ai besoin d'analyser l'origine - les origines, des passions", afirma (2016b: 22).

En el primer libro dedicado a la ciudad de su madre, titulado Osnabrück (1999), hallamos un pasaje que se abre con una frase en alemán: "MutTer, KANN ICH TRENNEN", que Ėve decía a su propia madre, frase "matricielle" o "motrice" (Delmotte-Halter, 2013: 8) que la narradora traduce así: "Mère puis-je séparer? Réparer puis séparer, réparer pour séparer puis-je Mère, puis-je séparer..." (Cixous, 1999: 219-220). De este modo, Cixous anula la destinalidad del nacimiento (el carácter biológico, determinante, inmodificable del hecho de nacer), por ejemplo cuando afirma: "Il y a des jours où Osnabrück est un rêve. Des jours où je suis née à Osnabrück. Naturellement je n'y étais pas encore. J'allais y apparaître. Il y a ces jours où Osnabrück est dans mon enfance à Oran. J'allais naître" (1999: 14).

Aunque los orígenes no nos determinen de forma absoluta, no nos aten a una identidad prefijada y permanente, Cixous piensa que tenemos

11. Por alusión al artículo de Cixous “La poésie comme contrepoison” (1981). 
el deber de responder ante ellos, "du moins pendant les siècles où les fantômes sont encore en fonction" (2016a: 146). Es por ello por lo que la narradora de Gare d'Osnabrück à Jérusalem afirma haber ido allí "en tant que juive", pero también "en tant que nonjuive [...] donc en tant que juiveselon, en tant que femme et fille et aussi juive comme fille de ma mère d'Osnabrück" (2016a: 147). Volvemos a una aparente contradicción, esta vez entre el deber de responder y el derecho a la no pertenencia, a rechazar, en palabras de Jacques Derrida, la entrada "violente, dissymétrique dans la communauté - dissymétrique, parce qu'il n'y a pas de contrat", una entrada que es "condition violente du partage" (en Cixous \& Derrida, 2004: 91).

\subsection{Las lenguas maternas en plural}

La cuestión de la lengua materna, que también se debe emplear siempre en plural en relación con Hélène Cixous, está estrechamente ligada a la de los orígenes. En Une autobiographie allemande, la escritora afirma:

Alors que je ne croyais pas pouvoir jamais surmonter un mystérieux exil originaire, comme je voyais s'éloigner de mes voux la Ville si chère de mes mères, j'ai été ramenée encore vivante à Osnabrück ville allemande, cependant que ma mère s'en allait en emportant l'allemand avec elle (2016b: 14).

Este "exilio originario" no lo es respecto de un país en el sentido usual, geográfico, del término (Cixous no ha calificado nunca de exilio su alejamiento de Argelia), sino respecto a una lengua-ciudad (o una "langueville-pays"; 2016b: 21), el exilio de una madre, de la lengua materna en tanto que lengua de la madre, de las madres en plural.

En la segunda página de Gare d'Osnabrück à Jérusalem hallamos esta frase: "Osnabrück est ce livre de ma mère qui sent allemand en français" (2016a: 14), que alude a la mezcla de dos lenguas, el francés y el alemán (venidos de la infancia de Hélène Cixous, "enfance à doublelangue"; 2016b: 21), muy presentes en este texto. Éste es quizás el libro, de entre toda la obra anterior de Cixous, que ofrece una hospitalidad más generosa a una lengua otra que el francés de la escritura, aunque este término, "francés", también debería ponerse en plural, ya que toda lengua 
contiene muchas otras lenguas, según la escritora: “Pour moi [...] il n’y a qu'une langue et elle parle parfois anglais, ou tantôt elle chante allemand, c'est un fleuve sonore où se jettent tant d'affluents" (2016b: 35; énfasis en el original).

En la frase citada en primer lugar ("Osnabrück est ce livre de ma mère qui sent allemand en français"), cabe remarcar que "alemán" y "francés" no llevan artículo que los singularice. Lo que destaca más, sin embargo, es el uso del verbo sentir (oler) en lugar de entendre (oír). El Trésor de la Langue française dice que sentir significa percibir "par l'intermédiaire des sens (excepté la vue et l'ouïe)", que son, paradójicamente, los únicos sentidos que utilizamos para leer, por lo menos en apariencia. Este libro olería alemán, como uno de los platos que cocinaba la madre o la abuela materna, pero quizás también tendría un tacto alemán, si atendemos a la teoría desarrollada por Cixous, especialmente en relación con la obra de Clarice Lispector, sobre la cercanía entre la vista y el tacto.

Gare d'Osnabrück à Jérusalem acoge también de forma hostipitalaria ${ }^{12}$ otro alemán, el que hablaban los carteles, reproducidos en las ilustraciones del libro, que transmitían mensajes de odio antisemita deslizados en anuncios de comercios o de lugares donde pasar vacaciones placenteras, en un mismo lenguaje publicitario: "Les Juifs sont indésirables", apunta el anuncio de un hotel balneario (en la traducción realizada por Cixous); otro trata de vendernos una playa "bien allemande et sans pollution juive". Otros rezan: "Noël chrétien - Profit juif" y "Qui au Juif apporte une somme de ses propres poings s'assomme" (2016a: s.p.). Este último resulta especialmente siniestro, ya que se hace eco de las "rimas" que Ève gustaba de componer para hacer reír.

Estas expresiones y frases, extraídas de la realidad histórica y familiar (pues los anuncios corresponden a los que veía la familia materna en Osnabrück en los años treinta), son, al mismo tiempo, ejemplos de la "banalidad del mal" de la que hablaba Hannah Arendt (2013); hay otros ecos de Arendt en el texto, por ejemplo en el uso del término "aparecer", pero sobre todo en relación con la "natalidad", que Arendt opone a la "mortalidad" como lo propio del ser humano según la teoría heideggeriana, y que utiliza como metáfora, como el "nacer" en Cixous. Estas frases recuerdan también el ensayo de Victor Klemperer (2002) sobre la "lengua

12. Según el concepto forjado por Derrida (1997), que combina "hospitalidad" y "hostilidad". 
del Tercer Reich", que este universitario escribió (al mismo tiempo que su Histoire de la littérature française du XVIII ${ }^{e}$ siècle, otro caso del poder salvador de la literatura) en una Judenhaus de Dresde; el autor se salvó de la deportación gracias al hecho de que su esposa Eva era "aria". Siguiendo la tradición filológica alemana, pero al principio en forma de cuaderno o diario, Klemperer muestra cómo los nazis manipularon y pervirtieron la lengua alemana para servir sus fines ideológicos; para él, la resistencia empezaba por darse cuenta de ello y rechazar el uso de esta "neolengua" (Orwell, 2014).

Gare d'Osnabrück à Jérusalem parece sugerir, pues, que el alemán es en realidad dos (o más) lenguas, una de las cuales sería una per-versión de la auténtica, como Klemperer apunta. O quizás, más de acuerdo con lo que afirma Derrida, contradiciendo la defensa que hace Arendt de la lengua alemana al exonerarla de toda responsabilidad en la deriva nazi, esta pluralidad se halla en el seno de la misma lengua:

[...] pour que les "sujets" d'une langue deviennent "fous", pervers ou diaboliques, mauvais d'un mal radical, il a bien fallu que la langue n'y fût pas pour rien; elle a dî avoir sa part dans ce qui a rendu cette folie possible; un être non parlant, un être sans langue "maternelle" ne peut pas devenir "fou", pervers, méchant, meurtrier, criminel ou diabolique (1996a: 104).

Cixous lo expresa por su parte como una "maladie de la langue", "une peste qui s'est répandue dans la ville" (2016a: 69), y que concreta en una serie de palabras terminadas en -ung que se revuelven contra su amo mordiéndole en el pie como Fips, el perro de su infancia en Argelia (Cixous, 2001). Todos estos ejemplos caracterizan otro de los rasgos que constituyen la singularidad de la escritura autobiográfica de Hélène Cixous, su mezcla de relato de historias vividas con una reflexión teórica que resuena con la de otros filósofos y escritores.

\subsection{Una autobiografía (entre otras)}

El carácter plural que Hélène Cixous otorga a conceptos aparentemente singulares por esencia (ciudad natal, lengua materna...) se aplica al concepto mismo de autobiografía. Casi al mismo tiempo que Gare d'Osnabrück à 
Jérusalem apareció Une autobiographie allemande (2016b) que recoge una correspondencia en forma de preguntas y respuestas entre la escritora Cécile Wajsbrot y la propia Hélène Cixous. Ésta había rechazado hasta el momento, salvo en casos puntuales, el uso del término "autobiografía", a causa de sus connotaciones determinantes: auto se refiere al sí mismo, en singular, y bios a la vida, también en singular. "Autobiografía" parece sugerir que escribir la propia vida equivale a fijarla en un relato, ya que la autobiografía supone una narración, mientras que Cixous afirma: "En général je ne raconte pas avec l'écriture. Avec l'écriture, je peins, - quoi? le peuple des pensées et des visions, les passages, pas les pas" (2016b: 28; énfasis en el original).

Asimismo, una de las definiciones genéricas más comunes de la autobiografía presupone que ésta establece un "pacto" (Lejeune, 1975), un contrato firmado entre $e l$ autor y el lector, en el cual el primero se compromete a decir la "verdad"; leemos en Gare d'Osnabrück à Jérusalem, en cambio: "On ne peut pas dire la vérité, dis-je, aucun livre, je ne peux pas, on ne pourra jamais, dire la vérité, et c'est dommage. Et c'est heureux. Au lieu de cette Illusion on peut tout dire, et ce sera de la vérité inventée" (2016a: 76). Cixous opone así la "información" que hoy día se encuentra tan fácilmente en Internet a la "ficción", mucho más verdadera: "Je préfère avoir la liberté de la fiction" (2016a: 135). La escritora apuesta, pues, por la ficción en lugar de lo real, o más bien por la literatura y el arte en lugar del "comentario" autobiográfico: "toute la scène est devenue mythologique, et donc j'ai eu l'assurance que cette fois nous nous trouvions dans une ville de la littérature. Tout était métaphore et métonymie. Invention et citation" (2016a: 91).

El artículo indeterminado del título Une autobiographie allemande ejerce así de antídoto contra la autobiografía con artículo bien determinado y singular. Al mismo tiempo, según su autora, Gare d'Osnabrück à Jérusalem no puede calificarse de "novela" sino que es "l'hématome causé par le choc qui s'est produit entre la Ville et le moi indéfini avec tous mes livres à ses côtés et soixante-dix ans de récits homériques proférés par ma mère [...] Un choc de surprise et d'amour" (2016a: 139). La ficción no equivale, para la autora, a la novela, que es un relato recompuesto como la autobiografía, mientras que los "recuerdos" que pueblan este libro no son esencialmente distintos de los "fantasmas" y de los "sueños" (2016a: 94).

El plural implícito en "una autobiografia" alude, pues, a las múltiples 
posibilidades del recuerdo, de la fantasía, del sueño, así como al parentesco entre ficción y autobiografía (o entre ficción y "testimonio", tal como analizó Derrida, 1996b), y también entre autobiografía y (alo)biografía, ya que Gare d'Osnabrück à Jérusalem esboza las biografías de esta “multitud de muertos" que acogió a la autora durante su viaje a Osnabrück, viaje real que ella sin embargo cuestiona cuando se pregunta si en verdad estuvo allí. Otro matiz semántico que podría conllevar este plural sería su alusión al vértigo de las nuevas identidades que se ofrecían ante los judíos que pudieron escapar de la persecución nazi, empezando en ocasiones vidas totalmente nuevas, vividas en lenguas también nuevas:

La perspective de devenir un autre, est un tourment auquel aucun candidat n'échappe, c'est-à-dire de désinvestir du jour au lendemain le devenir (allemand) dans lequel on avait installé ses habitudes d'être, sa langue, sa mémoire depuis les commencements de sa mémoire [...] (2016a: 124; énfasis en el original).

A modo de conclusión, cabría afirmar que Hélène Cixous lleva el género autobiográfico a sus límites, no tanto por su mezcla con la ficción novelesca (lo cual queda recogido en el término de "autoficción", que puede aplicarse, como hemos visto, a la obra de diversas escritoras francesas contemporáneas), sino por la pluralización que efectúa de varios elementos clave en este género, como son, entre otros, el origen individual (el nacimiento) y colectivo (la pertenencia a una comunidad, un entorno familiar y social determinado), la lengua materna, así como la memoria personal y los propios recuerdos. Gare d'Osnabrück à Jérusalem se asimila, pues, tanto a un libro de Historia y a un ensayo como a un relato autobiográfico, sin que podamos distinguir cuál es su carácter predominante. En cualquier caso, se trata de "literatura", tal como afirma su propia autora cuando dice que el poder de la literatura reside en su capacidad para hablar de las "tragedias" en minúscula que componen la "Tragedia" histórica (2016a: 68), en este caso el genocidio judío en manos de los nazis.

La literatura tiene el derecho y el deber de "decirlo todo", en palabras de Derrida (1993: 65), quien precisa: "Il y a dans la littérature, dans le secret exemplaire de la littérature, une chance de tout dire sans toucher au 
secret", pues la literatura no pertenece ni a lo "privado" ni a lo "público" (1993: 54). Ello explica por qué la obra de Hélène Cixous se aleja de las polémicas públicas que provocan las autoficciones de otras escritoras contemporáneas, acusadas de traicionar "secretos" ajenos, aun siendo una escritura comprometida con una responsabilidad política, asumida sin reparos por la misma autora: "l'acte littéraire n'a jamais été dissocié pour moi de sa mission politique" (2016b: 90).

\section{REFERENCIAS BIBLIOGRÁFICAS}

ANGOT, Ch. (1999). L'Inceste. París: Stock. (2000). Quitter la ville. París: Stock.

ARENDT, H. (2013). Eichmann en Jerusalén. Barcelona: Lumen.

BENSTOCK, Sh. (ed.) (1988). The Private Self: The Theory and Practice of Women's Autobiographical Writings. Chapel Hill-Londres: University of North Carolina Press.

BOYER-WEINMANN, M. (2013). Vieillir dit-elle: une anthropologie de l'âge. Seyssel: Champ Vallon.

BRÉE, G. (1986). “Autogynography”. The Southern Review 22, 223-230. BRODZKI, B. \& SCHENCK, C. (eds.) (1988). Life/Lines: Theorizing Women's Autobiography. Ithaca-Londres: Cornell University Press.

CIXOUS, H. (1975). "Le rire de la Méduse". L'Arc 61, 39-54. (1981). "La poésie comme contrepoison". Le Nouvel Observateur, mayo.

(1997). OR - les lettres de mon père. París: Des femmes-Antoinette Fouque.

(1999). Osnabrück. París: Des femmes-Antoinette Fouque. (2000a). Les Rêveries de la femme sauvage. París: Galilée. (2000b). Le Jour où je n'étais pas là. París: Galilée.

(2001). "Stigmates". Lectora. Revista de dones $i$ textualitat 7, 195210.

(2008). Ciguë. Vieilles femmes en fleurs. París: Galilée.

(2010). "Volées d'humanité". En Rêver croire penser: autour d'Hélène Cixous, B. Clément \& M. Segarra (eds.), 15-37. París: CampagnePremière. 
(2011). Revirements - dans l'antarctique du cour. París: Galilée. (2013). Abstracts et Brèves Chroniques du temps. I. Chapitre Los. París: Galilée.

(2015). Corollaires d'un væu. Abstracts et Brèves Chroniques du temps II. París: Galilée.

(2016a). Gare d'Osnabrück à Jérusalem. París: Galilée.

(2016b). Une autobiographie allemande. París: Christian Bourgois. (2017). Conversation avec le mur. París: Galilée.

CIXOUS, H. \& DERRIDA, J. (2004). Lengua por venir/Langue à venir. Seminario de Barcelona, M. Segarra (ed.). Barcelona: Icaria.

COLONNA, V. (1989). Essai sur la fictionalisation de soi en littérature (Tesis doctoral). París: École de Hautes Études en Sciences SocialesEHESS.

(2004). L'Autofiction et autres mythomanies littéraires. Auch: Tristram.

DARRIEUSSECQ, M. (1996). "L'autofiction, un genre pas sérieux". Poétique 107, 369-380.

DELAUME, Ch. (2010). La Règle du Je. París: Presses Universitaires de France.

DELMOTTE-HALTER, A. (2013). "Le cru de l'écrit ou les archives de la sauvagerie", Flaubert. Revue critique et génétique 10, http:// flaubert.revues.org/2116 [24/07/ 2017].

DERRIDA, J. (1993). Passions. París: Galilée.

(1996a). Le Monolinguisme de l'autre. París: Galilée.

(1996b). "Demeure. Fiction et témoignage". En Passions de la littérature. Avec Jacques Derrida, M. Lisse (ed.), 13-73. París: Galilée.

(1997). De l'hospitalité. Anne Dufourmantelle invite Jacques Derrida à répondre. París: Calmann-Lévy.

DIDIER, B. (1981). L'Écriture-femme. París: Presses Universitaires de France.

DJEBAR, A. (1985). L'Amour, la Fantasia. París: Jean-Claude Lattès.

DOUBROVSKY, S. (1977). Fils. París: Galilée.

FASSIN, É. (2001). "Le 'double je' de Christine Angot: Sociologie du pacte littéraire". Sociétés \& Représentations 11 (1), 143-166.

GENETTE, G. (1991). Fiction et Diction. París: Seuil.

HEWITT, L.D. (1990). Autobiographical Tightropes: Simone de Beauvoir, 
Nathalie Sarraute, Marguerite Duras, Monique Wittig and Maryse Condé. Lincoln: University of Nebraska Press.

HUBIER, S. (2003). Littératures intimes: Les expressions du moi, de l'autobiographie à l'autofiction. París: Armand Colin.

JACCOMARD, H. (1993). Lecteur et lecture dans l'autobiographie française contemporaine: Violette Leduc, Françoise d'Eaubonne, Serge Doubrovsky, Marguerite Yourcenar. Ginebra: Droz.

KLEMPERER, V. (2002). La lengua del Tercer Reich. Barcelona: Minúscula.

LEBELLEY, F. (1994). Duras ou le poids d'une plume. París: Grasset.

LECARME, J. \& LECARME-TABONE, É. (1999). L'Autobiographie. París: Armand Colin ( $2^{\mathrm{a}}$ ed.).

LEJEUNE, Ph. (1975). Le Pacte autobiographique. París: Seuil.

MICHAUX, H. (1945). Épreuves, exorcismes. París: Gallimard.

ORWELL, G. (2014). 1984. Barcelona: Lumen.

SMITH, S. (1987). A Poetic of Women's Autobiography: Marginality and the Fictions of the Self-representation. Bloomington: Indiana University Press.

(1993). Subjectivity, Identity, and the Body: Women's Autobiographical Practices in the Twentieth Century. Bloomington: Indiana University Press.

SMITH, S. \& WATSON, J. (eds.) (1992). De-Colonizing the Subject: The Politics of Gender in Women's Autobiography. Minneapolis: University of Minnesota Press.

(1998). Women, Autobiography, Theory: A Reader. Madison: University of Wisconsin Press.

STANTON, D. C. (1987). “Autogynography: Is the Subject Different?”. En The Female Autobiograph. Theory and Practice of Autobiography from the Tenth to the Twentieth Century, D. C. Stanton (ed.), 3-20. Chicago: The University of Chicago Press.

THUMEREL, F. (2004) (ed.). Annie Ernaux, une ouvre de l'entre-deux. Arras: Artois Presses Université.

VIART, D. \& VERCIER, B. (2005). La Littérature française au présent. París: Bordas.

VIGAN, D. de (2011). Rien ne s'oppose à la nuit. París: Jean-Claude Lattès.

(2015). D’après une histoire vraie. París: Jean-Claude Lattès. 
Recibido el 15 de mayo de 2017.

Aceptado el 15 de septiembre de 2017. 
